\title{
Regulation of Cholesterol Metabolism in the Dog
}

\author{
II. EFFECTS OF COMPLETE BILE DIVERSION \\ AND OF CHOLESTEROL FEEDING ON POOL SIZES \\ OF TISSUE CHOLESTEROL MEASURED AT AUTOPSY
}

Demetrius Pertsemtidis, Ernest H. Kirchman, and E. H. Ahrens, Jr.
From The Rockefeller University, New York 10021 and the Department of
Surgery, Mount Sinai School of Medicine, City University of New York 10029

A B S T R A C T In six adult pedigreed dogs the effects of high-cholesterol diets or bile diversion on the sizes of body cholesterol pools were studied at autopsy. Total body cholesterol was determined by measuring the cholesterol content of discrete organs and of the eviscerated carcass: neither cholesterol feeding nor bile diversion had altered total body cholesterol or the cholesterol content of individual organs and tissues. These results validated the conclusion based on sterol balance data obtained during life, that high-cholesterol feeding did not lead to substantial expansion of tissue cholesterol pools.

The total amount of exchangeable cholesterol in the animals with an intact enterohepatic circulation, when estimated from isotopic data, was essentially the same as that measured chemically: this indicated that there was little or no nonexchangeable cholesterol in these dogs, except in skin and nervous tissue, regardless of the cholesterol content of the diet. This correspondence of estimates was not obtained in the bile-diverted dogs: we propose that the defect in the isotopic estimates was due to the accelerated rate of cholesterol synthesis in these animals.

Gross and microscopic morphology of all organs and tissues was examined. Abnormal findings were limited to the biliary tract and the urinary collecting system of the two bile-diverted dogs: multiple bilirubinate gallstones were found, and mild pyelitis and ureteritis were present on the side of the bilio-renal shunt, but the urinary bladder was normal. Histologic evidence of moderate degree of cholangitis was found in one of the two bile-

Dr. Pertsemlidis' and Dr. Kirchman's present address is Department of Surgery, Mount Sinai School of Medicine, City University of New York.

Received for publication 19 August 1972 and in revised form 19 April 1973. shunted dogs, but in neither dog was there evidence of impedance of bile flow.

\section{INTRODUCTION}

Total body cholesterol is regulated by a complex dynamic interplay between absorption, synthesis, and excretion. Any imbalance among these principal determinants might result in swelling or depletion of the exchangeable body pools of cholesterol, and it might be expected that the size of the plasma cholesterol pool would reflect such imbalances. This expectation is not always borne out: for instance, when unsaturated fat was fed to a series of hypercholesterolemic patients (1), plasma cholesterol concentrations fell without measurable changes in synthesis, absorption, or excretion. In that case the results obtained led to the proposal that cholesterol simply shifted out of the plasma into various as yet undefined tissue compartments.

In the accompanying report (2) we showed in the dog during life that, when large amounts of cholesterol were fed for many months, the increment in absorbed dietary cholesterol was compensated by virtually complete repression of cholesterol synthesis and increased excretion of fecal bile acids. These two compensatory mechanisms appeared to be effective in preventing substantial accumulation of cholesterol in body pools, even though significant increases in plasma concentrations were evident. It was also shown that complete interruption of the enterohepatic circulation of cholesterol and bile acids resulted in very large increases of cholesterol synthesis because of the total absence of feedback control. Although plasma cholesterol concentrations consistently fell, we had no way to measure changes in body pools during life in these dogs. 
We asked the following questions: was synthesis totally suppressed by cholesterol feeding, as predicted by sterol balance and isotope kinetic studies? Was there an expansion of the tissue stores of cholesterol when plasma levels were increased by the feeding of high-cholesterol diets? Was a prolonged decrease in plasma cholesterol concentrations, caused by prolonged bile diversion accompanied by depletion in tissue cholesterol contents? Were all tissue pools of cholesterol (exclusive of the central nervous system) in equilibrium with cholesterol in the plasma at the time of death, as judged by specific activity analyses after administration of radioactive cholesterol before sacrifice?

The data presented in this report showed, first, that a high-cholesterol intake over many months did not lead to an accumulation of cholesterol in any tissue; inhibition of synthesis and re-excretion of absorbed cholesterol as bile acids adequately compensated for the large dietary intake. Second, after bile diversion for almost $2 \mathrm{yr}$ and prolonged reductions in plasma cholesterol concentrations, tissue cholesterol contents (total body cholesterol. discrete organ cholesterol content, and tissue cholesterol concentrations) remained unchanged. Third, complete isotopic equilibrium was demonstrated between plasma and all other tissues (except the nervous system and skin) in the dogs in which the enterohepatic circulation was not interrupted. In bile-shunted dogs, however, specific activities of tissues were consistently higher than that of the plasma. Finally, we could find no evidence for nonexchangeable or very slowly exchangeable pools of cholesterol in any tissues except the nervous svstem and skin.

\section{METHODS}

The clinical and dietary management of the six dogs, as well as the experimental design and laboratory data obtained during life, are described in full in the accompanying report (2). In $\operatorname{dogs} E$ and $F$, biopsies of adipose tissue, skeletal muscle, liver, and right kidney were taken at the time of cholecystonephrostomy to compare their cholesterol concentrations with those at the time of death $2 \mathrm{yr}$ later. Tissue biopsies were also taken from control dog A 14 mo before sacrifice.

Timing of sacrificc. The bile-diverted and control dogs were each given a single dose of $\left[4{ }^{14} \mathrm{C}\right]$ cholesterol intravenously $2-5$ wk before death; these animals were sacrificed during the log-linear phase of the decay of plasma cholesterol. The $\left[{ }^{3} \mathrm{H}\right]$ cholesterol-fed dogs were sacrificed after the isotopic steady state had been attained, i.e., when the specific activity of plasma $\left[{ }^{3} \mathrm{H}\right]$ cholesterol equaled that of dietary cholesterol, and the daily excretion of $\left[{ }^{3} \mathrm{H}\right]-$ cholesterol (in the form of fecal neutral plus acidic steroids) was equal to its intake (2).

Technique of sacrifice. The animals were bled to death under anesthesia with intravenous sodium thiamylal (30 $\mathrm{mg} / \mathrm{kg}$ body weight). Through a cannula in the femoral artery the blood was collected in vacuum bottles containing citrate solution; the total blood volume was measured, and portions of plasma and whole blood were analyzed sepa- rately and in duplicate for cholesterol mass and specific radioactivity. Extensive efforts were made to minimize the amount of blood remaining in the eviscerated carcass and tissues; residual blood in the eviscerated carcass was collected on sponges and included in the total blood volume.

The entire skin was removed, weighed, and treated as a single specimen; however, the quantity of subcutaneous fat removed with the skin from the carcass was quite variable. All discrete organs were removed from the carcass and weighed; representative tissue samples were taken for analysis of cholesterol mass and specific radioactivity (in duplicate) as well as for histologic studies. Skeletal muscle was taken from quadriceps and psoas; adipose tissue samples from subcutaneous, omental, and perinephric sites. Fullthickness samples were taken from esophagus, stomach, small intestine, and colon after their contents were carefully washed away. Separate specimens of renal cortex and medulla were collected. Brain samples taken from the parietal lobe consisted of about equal parts of gray and white matter. In three $\operatorname{dogs}(A, B$, and $F$ ) the brain and spinal cord were removed and treated separately; in two dogs ( $C$ and $E$ ) the brain was removed but the spinal cord was left with the eviscerated carcass; and ine one dog (D) the brain and spinal cord were left with the carcass. Thus, in three dogs the "carcass" represented the remnant of the body after removal of skin (with some subcutaneous fat) and all discrete organs including the central nervous system (CNS), while in the other three, various amounts of nervous tissue remained with the eviscerated carcass.

Measurement of tissue cholesterol mass and radioactivity. Portions of discrete organs (in duplicate) weighing about $1.5 \mathrm{~g}$ (wet weight) were subjected to mild alkaline hydrolysis and extracted with petroleum ether. After preliminary thin-layer chromatography (TLC) on Florisil (Florisil Analytical Adsorbents, Floridin Co., Tallahassee, Fla.) with diethyl ether heptane $(45: 55, \mathrm{vol} / \mathrm{vol})$, total cholesterol content and radioactivity were quantified by gas-liquid chromatography (GLC) and isotope counting as described previously (3). Total radioactivity in organ extracts was measured before and after TLC, to correct for losses during TLC. In addition, $\beta$-sitosterol added to the extracts as a recovery standard was measured after TLC: recoveries were $86.5 \%$ for radioactive cholesterol and $84 \%$ for $\beta$-sitosterol.

The eviscerated carcass and skin specimens were saponified in $n$-ethanolic $\mathrm{NaOH}$ solution (2 liters $/ \mathrm{kg}$ tissue) in separate steel vats; for one dog, ethanolic $\mathrm{KOH}$ was used. The solution was brought to a gentle boil maintained throughout the saponification period: the skin dissolved completely in $3 \mathrm{~h}$, the eviscerated carcass in 12-24 h (some of the bone remained undissolved; it was ground up, resaponified, and analyzed separately). These hydrolyses yielded dark brown, homogenous, almost translucent liquids with negligible sediment; the skin solution was diluted with water to keep it liquid at room temperature. Four to eight samples of 5-10 ml were taken from each solution for measurement of cholesterol mass and radioactivity. For $\operatorname{dogs} B$ and $F, \beta$-sitosterol was added as a recovery standard during the saponification of carcass and skin: recoveries were $86 \%$ for carcass and $84 \%$ for skin. In other dogs, radioactive cholesterol was added as an internal standard to the carcass and skin: recoveries were 91 and $87 \%$, respectively. Final calculations were appropriately corrected by means of these recovery data.

Kinetic analysis. Pool sizes of exchangeable cholesterol were estimated by input-output analysis (4) of specific 


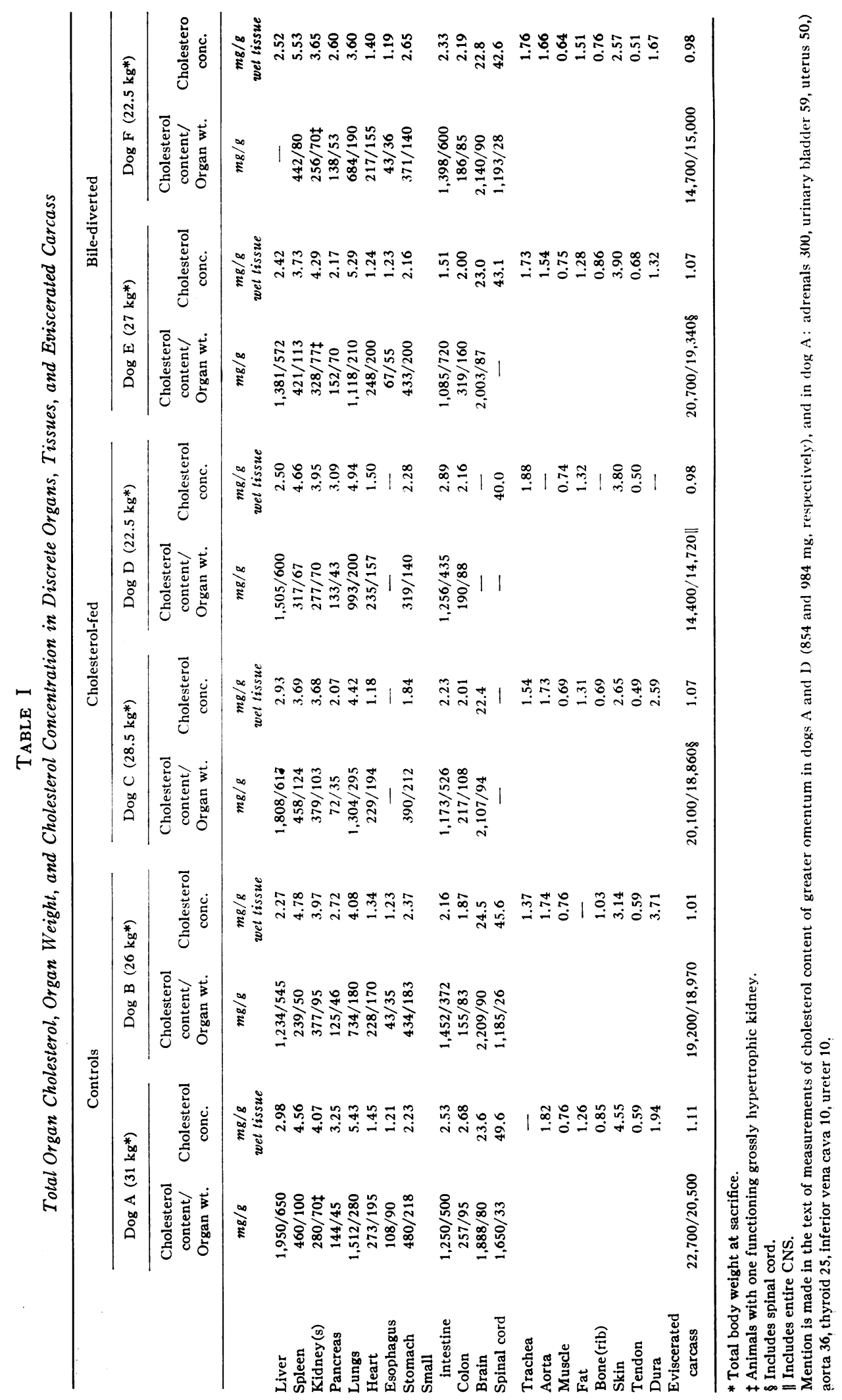

D. Pertsemlidis, E. H. Kirchman, and E. H. Ahrens, Jr. 
TABLE II

Cholesterol Concentration (mg/g Wet Tissue) in Surgical Biopsy Specimens and at Time of Sacrifice, about 2 yr later

\begin{tabular}{|c|c|c|c|c|c|c|}
\hline & \multirow{2}{*}{\multicolumn{2}{|c|}{$\begin{array}{l}\text { Control } \\
\text { Dog A }\end{array}$}} & \multicolumn{4}{|c|}{ Bile-diverted } \\
\hline & & & \multicolumn{2}{|c|}{$\operatorname{Dog} E$} & \multicolumn{2}{|c|}{$\operatorname{Dog} F$} \\
\hline & Biopsy & Autopsy & Biopsy & Autopsy & Biopsy & Autopsy \\
\hline Liver & 2.69 & 2.98 & 3.74 & 2.42 & 3.17 & 2.52 \\
\hline Kidney & 3.85 & 4.07 & 3.89 & 4.29 & 3.85 & 3.65 \\
\hline Muscle (skeletal) & 0.84 & 0.76 & 0.67 & 0.75 & 0.68 & 0.64 \\
\hline Fat & 1.45 & 1.26 & 1.44 & 1.28 & 1.16 & 1.51 \\
\hline
\end{tabular}

activity-time course curves of plasma cholesterol measured as described in the accompanying report (2).

\section{RESULTS}

The animals were judged to be healthy throughout the study and at the time of sacrifice (2). Intravenous cholangiography immediately before death in the bile-diverted dogs $E$ and $F$ showed patent biliorenal shunts with appearance of the dye in the distal right ureter and bladder; however, the presence of multiple radiolucencies suggested the existence of the gallstones that were indeed found at the time of death.

Tissue cholesterol concentration. Despite possible differences in degree of hydration of tissues, cholesterol concentrations in the three experimental groups were remarkably alike (Table I). Liver cholesterol concentration was not altered by either cholesterol feeding or bile diversion, nor was cholesterol concentration in the aorta. The tissues comprising the major reservoirs of body cholesterol, such as muscle, adipose tissue, and connective tissue (tendon), were also found to have about the same cholesterol concentration in each experimental group. The bone (rib) cholesterol content was not affected by prolonged bile diversion. The cholesterol content of skin was highly variable, but there were no apparent systematic differences between experimental groups. Although the sterol content of tendon was remarkably similar in the three groups, that in the dura was always higher and more variable from dog to dog. As expected, there were no differences in brain and spinal cord cholesterol.

The weight and total cholesterol content of certain discrete organs at the time of death are also shown in Table I. The dogs differed considerably in size and total body weight, hence there were large variations in organ weights among the six dogs and in cholesterol content per organ. Differences in total kidney cholesterol are difficult to interpret, since the bile-diverted dogs and one control animal (A) had only one functioning and grossly hypertrophic kidney at sacrifice. In two ani- mals, one control (A) and one cholesterol-fed (D), the greater omentum was treated as a separate specimen; it weighed 355 and $487 \mathrm{~g}$ and contained 854 and $984 \mathrm{mg}$ of cholesterol, respectively. In one control animal (A) some of the smaller discrete organs were analyzed in toto and found to contain the following total amounts of cholesterol (in milligrams): adrenal glands 300, urinary bladder 59 , uterus 50 , aorta 36 , thyroid 25 , inferior vena cava 10 , ureter 10 .

In the two bile-diverted and one control dog (A) surgical biopsies of four tissues had been obtained about $2 \mathrm{yr}$ before sacrifice for comparison with their concentration at the time of death (Table II). There were no marked differences, except for lower sterol concentrations in the livers of the bile-shunted animals.

Total body cholesterol. The total mass of tissue cholesterol at the time of sacrifice is shown in Table III: it ranged from 32.4 to $52.5 \mathrm{~g}$, or 1.44 to $1.69 \mathrm{~g} / \mathrm{kg}$ body weight.

The animal-to-animal variability in cholesterol content of the skin (and partly of the carcass) is due to unavoidable differences in dissection, since the amount of subcutaneous fat separated from the carcasses during removal of the skin varied considerably. "Bone" cholesterol in these experiments does not represent total sterol of the skeleton: during alkaline hydrolysis the bony structures were partially dissolved, with release of unknown amounts of sterol into the saponification solution. Bone dissolution and therefore release of bone cholesterol were greater in the bile-shunted dogs than in the other animals; this was probably due to mild metabolic bone disease caused by bile diversion. The cholesterol concentration of intact ribs taken immediately after death and analyzed separately (without prior saponification) showed similar values in each of the three groups of animals; this indicated that the existence of mild metabolic bone disease did not affect the cholesterol content of bone. The reduced total blood cholesterol in bile-shunted dogs was consistent with reductions in plasma cholesterol levels observed during life. 
TABLE III

Tissue, Blood, and Total Body Cholesterol Content at the Time of Death

\begin{tabular}{|c|c|c|c|c|c|c|}
\hline & \multicolumn{2}{|c|}{ Control } & \multicolumn{2}{|c|}{ Cholesterol-fed } & \multicolumn{2}{|c|}{ Bile-diverted } \\
\hline & A & B & c & D & $\mathrm{E}$ & $\mathbf{F}$ \\
\hline Total body weight, $\mathrm{kg}$ & 31 & 26 & 28.5 & 22.5 & 27 & 22.5 \\
\hline Eviscerated carcass, $\llbracket g /$ tissue & 22.7 & 19.2 & $20.1^{*}$ & $14.4 \ddagger$ & 20.78 & 14.7 \\
\hline Skin, $\llbracket g /$ tissue & 13.0 & 7.2 & 7.2 & 9.7 & 14.5 & 7.1 \\
\hline \multicolumn{7}{|l|}{ Discrete organs } \\
\hline (other than CNS) $\ddagger g /$ tissue & 8.2 & 5.0 & 6.0 & 6.2 & 5.6 & 4.9 \\
\hline Brain and spinal cord, $\sharp g / t i s s u e$ & 3.5 & 3.4 & $2.1 \S$ & - & $2.0 \S$ & 3.3 \\
\hline Bone, $\|^{* *} g /$ tissue & 0.7 & 0.7 & 0.6 & 0.7 & 0.3 & 0.2 \\
\hline Blood, ${ }^{* *} g /$ tissue & 4.2 & 3.3 & 3.6 & 2.8 & 2.4 & 2.2 \\
\hline Total body cholesterol, $g$ & 52.5 & 38.8 & 39.6 & 33.8 & 45.5 & 32.4 \\
\hline $\mathrm{g} / \mathrm{kg}$ & 1.69 & 1.50 & 1.47 & 1.50 & 1.60 & 1.44 \\
\hline Mean & \multicolumn{2}{|c|}{1.60} & \multicolumn{2}{|c|}{1.49} & \multicolumn{2}{|c|}{1.54} \\
\hline
\end{tabular}

* Includes spinal cord.

$\ddagger$ Includes spinal cord + brain.

$\$$ Brain only.

|| Bone remaining undissolved after saponification of the carcass for $24 \mathrm{~h}$.

T The mean of 4-8 replicate analyses.

** The mean of 2-4 replicate analyses.

\# The mean of duplicate analyses (mean difference between duplicates $=5.1 \%$ ).

The percent contribution of each fraction to total body cholesterol is shown in Fig. 1. From group to group the similarities were far more striking than the differences, particularly if the eviscerated carcass and skin are considered together.
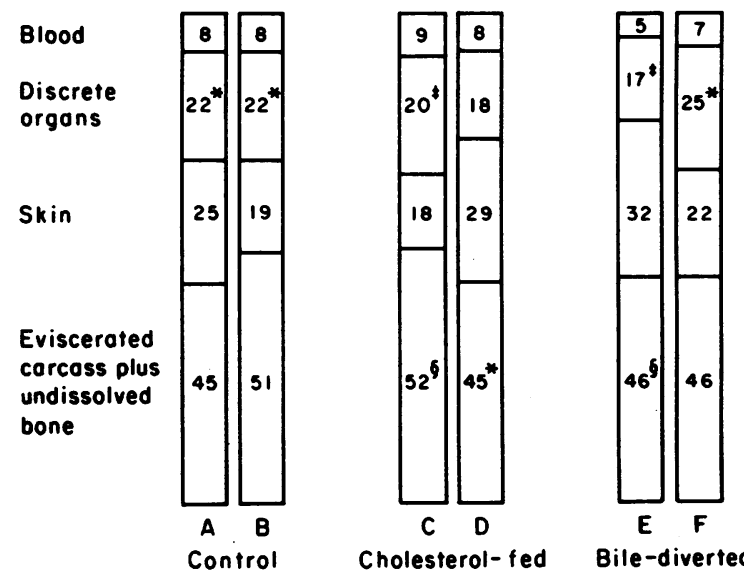

Figure 1 Sources of body cholesterol and their percentages of contribution to total body sterol. The total sterol mass of discrete organs varied from animal to animal, partly because of the various amounts of nervous tissue included in discrete organ sterol mass. The skin cholesterol quantity was the most variable because of the manner in which the dissection of subcutaneous fat was carried out; however, the total sterol of the eviscerated carcass plus skin was remarkably similar in each of the three groups.

* Includes brain and spinal cord.

¥ Includes brain but not spinal cord.

§ Includes spinal cord but not brain.
Distribution of radioactive cholesterol in tissues. The specific radioactivities of $\left[{ }^{14} \mathrm{C}\right]-$ and $\left[-^{8} \mathrm{H}\right]$ cholesterol in 22 tissues, and the ratios of these values to those in plasma are presented in Table IV. Despite wide differences in absolute values between the six dogs, the specific activities relative to plasma were remarkably close to unity in most tissues in the control and cholesterol-fed dogs. In the control dogs, the highest specific activity ratios were found in the adipose tissue, and the lowest in the skin, dura, and nervous tissue. In the dogs fed $\left[{ }^{3} \mathrm{H}\right]$ cholesterol to attain the isotopic steady state, the cholesterol specific activity ratios in all tissues outside the CNS were remarkably close to unity; the impossibly high results otbained in the liver of $\operatorname{dog} C$ could only be due to radioactive contamination of the samples analyzed.

In the bile-shunted dogs, by contrast, there were striking differences between tissue and plasma specific radioactivities, indicating incomplete mixing of plasma cholesterol with that in the tissues in which the specific activity ratios were very much greater than unity (all except liver and spleen) or very much less than unity (nervous tissue).

Estimation of total exchangeable body cholesterol by kinetic analysis. Table $\mathrm{V}$ presents our estimates of total exchangeable body cholesterol by the method of inputoutput analysis (4), compared to the chemical measurements made at time of sacrifice. (No data are given for $\operatorname{dog} E$ because the number of specific activity determinations were too few for satisfactory analysis.) 
TABLE IV

Specific Radioactivity in Tissues, $d p m / m g$ and Tissue/Plasma Ratios of $\left[4{ }^{14} \mathrm{C}\right]-$ or $\left[1,2-{ }^{3} \mathrm{H}\right]$ Cholesterol

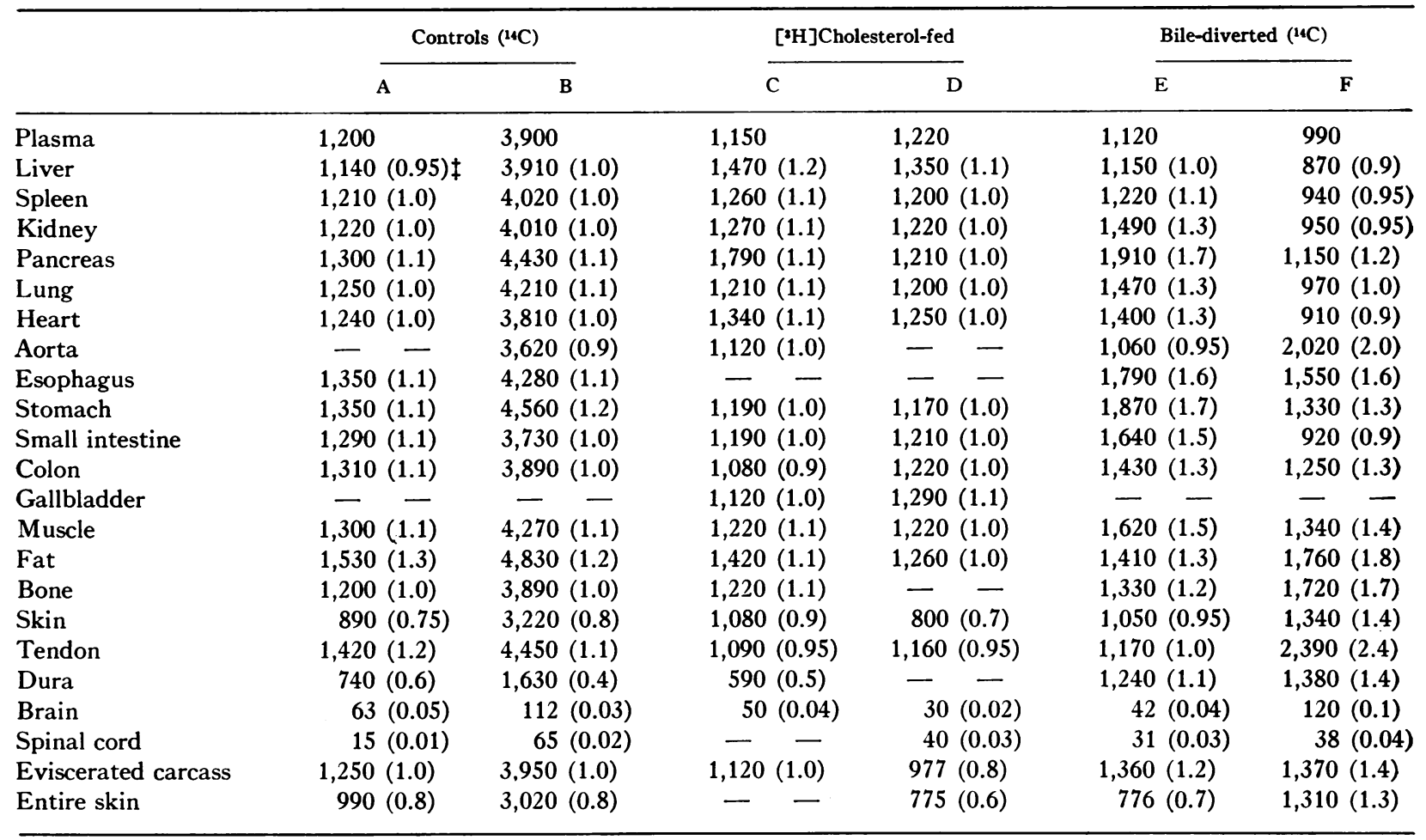

* Radioactive cholesterol in the tissues of dogs, A, B, E, and F was due to injection of a single intravenous dose of [4-14 C]cholesterol 2-5 wk before sacrifice. The timing of sacrifice coincided with the log-linear phase of the specific activity-time curve of plasma cholesterol in each dog. In dogs $\mathrm{C}$ and $\mathrm{D}$ radioactive cholesterol in the tissues resulted from the daily oral administration of $\left[1,2-{ }^{2} \mathrm{H}\right]$-cholesterol $(2.7-3.0 \mathrm{~g} /$ day for 7-9 mo before sacrifice); attainment of the isotopic steady state was proved in each dog before sacrifice.

$\ddagger$ Numbers in parentheses are the ratios of specific activity of cholesterol in each tissue relative to that in plasma at time of sacrifice.

As shown in Table $\mathrm{V}, \operatorname{dogs} \mathrm{A}, \mathrm{B}$, and $\mathrm{F}$ were sacrificed during the log-linear phase of the specific activity-time course curve; other analyses were made at earlier periods.

Pool size estimates for the minimum value for total exchangeable mass of cholesterol $(M)^{1}$ compared surprisingly well with actual measurements of total body cholesterol (excluding the nervous system and skin) made at sacrifice. Skin cholesterol was deducted from total body cholesterol because of the fact that a large amount of skin cholesterol arises in that organ by synthesis in situ, is excreted via the skin surface lipids, and hence is not in equilibrium with the rest of the body cholesterol. Table $\mathrm{V}$ indicates that this deduction was made in two ways, but at this stage it seems unprofitable to try to decide from so few data whether one or the other

${ }^{1}$ Abbreviation used in this paper: $M$, minimum value for total exchangeable mass of cholesterol; $M_{4}$, pool with rapid turnover; $M_{B}$, pool with slow turnover. deduction for skin cholesterol is preferable. On principle it would seem more logical to expect $M$ to relate more ideally to the total body cholesterol after deduction of CNS cholesterol plus that part of the skin cholesterol synthesized locally.

Lofland, Clarkson, and Bullock (5) reported a study in 49 squirrel monkeys in which they carefully compared chemical measurements of total body cholesterol at sacrifice with the results of kinetic analyses of specific activity-time course curves drawn during the metabolic steady state. $M$ (called by them "total traced mass" and computed by input-output analysis) was almost identical to the pool with rapid turnover $\left(M_{\Lambda}\right)$ plus the pool with slow turnover $\left(M_{B}\right)$ (minimum), computed by compartmental analysis according to Nestel, Whyte, and Goodman (6). (This, of course, was to be expected since the same basic data are fed into equations that are mathematically interconvertible, and in both approaches the calculation of $M_{B}(\mathrm{~min})$ assumes that all cholesterol 
TABLE V

Comparative Estimates of Total Exchangeable Body Cholesterol Pools by Kinetic Analysis (4) and Direct Measurement

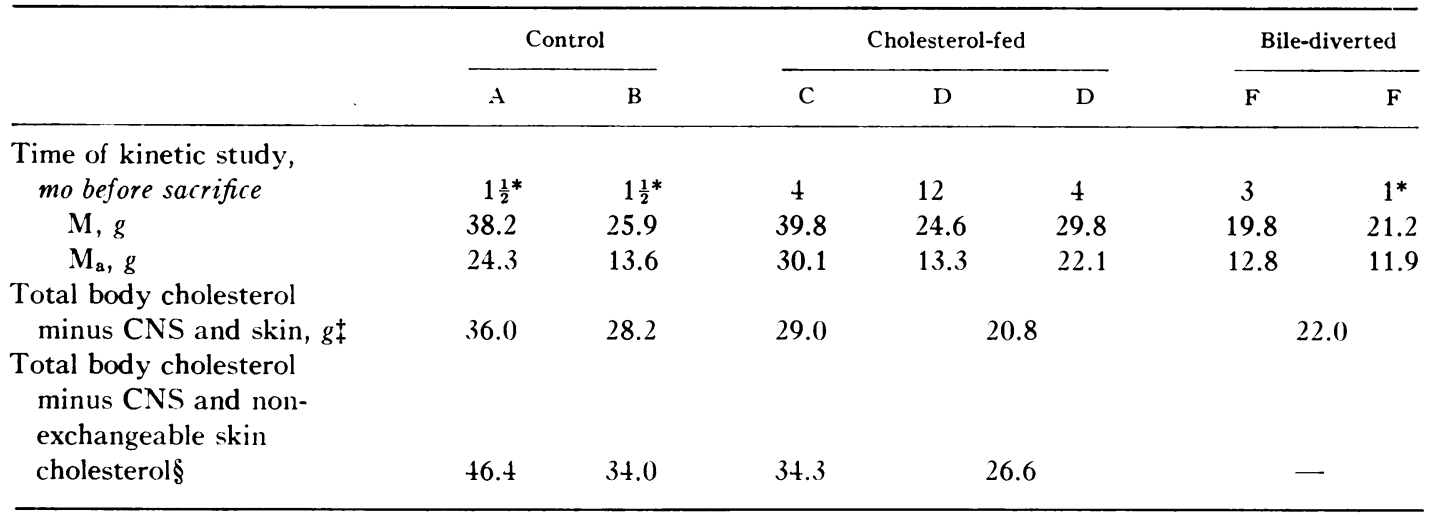

* Kinetic data by input-output analysis (4) were obtained shortly before or several months before sacrifice, as indicated.

¥ Chemical measurements are based on data in Table III. For dog D the CNS cholesterol was taken to be $3.4 \mathrm{~g}$ (the mean in $\operatorname{dog} \mathrm{A}, \mathrm{B}$, and $\mathrm{F}$ ).

$\S$ Nonexchangeable skin cholesterol $=$ total skin cholesterol $($ Table III) $\times$ [entire skin cholesterol sp ac $\div$ plasma cholesterol sp ac at sacrifice (Table IV)]. In dog C, the specific activity ratio of the "entire skin" was not measured; hence, the mean of the ratios found in $\operatorname{dogs} \mathrm{A}, \mathrm{B}$, and $\mathrm{D}(0.73)$ was used in calculating the nonexchangeable skin cholesterol for this animal. This could not be calculated in dog F, since its skin cholesterol specific activity was higher than that in the plasma (see Table IV).

input occurs in the pool with rapid turnover.) But, of still greater relevance was the near identity between the kinetic estimates of total exchangeable cholesterol pool size and the chemical measurements made at sacrifice after removal of all CNS tissue and intestinal contents (see their Table V): in six monkeys fed a lowcholesterol lard diet, $M=1,418 \mathrm{mg}, M_{A}+M_{B}(\min )=$ $389+1,029=1,418$; $\quad$ chemical measurement $=1.402$. In 40 other monkeys fed cholesterol-rich diets for $2 \mathrm{yr}$ before sacrifice (where the fat content was made up variously of safflower, butter, and coconut oils, and lard), the correspondence between chemical and kinetic measurements of total exchangeable body cholesterol was not always so close, the kinetic approaches underestimating the true masses in some animals. They attributed this disparity to "failure of the die-away curves to reach their final exponential rates ... and invalid assumptions used by others in relating hypothetical twopool models to cholesterol metabolism in animals having expanded whole body pools."

Estimation of exchangeable carcass cholesterol from tissue specific activity data. The animals were sacrificed after attainment of the isotopic steady state (with constant oral intake of radioactive cholesterol) or during the log-linear phase of the plasma cholesterol specific radioactivity curve (after single intravenous injection of radioactive cholesterol). Under these conditions it was possible to measure the total exchangeable pool of cholesterol in the eviscerated carcass (free of skin and nervous tissue) as follows:

Total exchangeable carcass cholesterol $(\mathrm{mg})=$ Total carcass $\left[{ }^{14} \mathrm{C}\right]$ - or $\left[{ }^{3} \mathrm{H}\right]$ cholesterol $(\mathrm{dpm}) /$ Plasma $\left[{ }^{14} \mathrm{C}\right]$ or $\left[{ }^{3} \mathrm{H}\right]$ cholesterol at the time of death $(\mathrm{dpm} / \mathrm{mg})$

The results obtained for carcass cholesterol and for exchangeable pools are given in Table VI. The calculated and determined exchangeable pools were remarkably similar in the control and cholesterol-fed dogs. Thus, it appeared that all of the cholesterol in the eviscerated carcass (excluding that of the skin and CNS) consisted of readily exchangeable cholesterol. These calculations and the close proximity of $\left[{ }^{\mathrm{H}} \mathrm{C}\right]$ - or $\left[{ }^{8} \mathrm{H}\right]$ cholesterol specific activity between tissues and plasma in control and cholesterol-fed dogs at the time of death (Table IV) indicated that there were no significant nonexchangeable or very slowly exchangeable pools in tissues other than the brain and spinal cord.

Table VI also demonstrates that the calculation from isotope data of total exchangeable carcass cholesterol in the bile-diverted dogs was grossly in error, as might have been predicted from the lack of correspondence between plasma and tissue specific activity data shown in Table IV.

Morphologic findings. In the control and cholesterolfed dogs no gross abnormalities were evident in any of 
TABLE VI

Measurement of Exchangeable Cholesterol in the Eriscerated Carcass

(Exclusive of Skin and Nervous Tissue)

(Comparison of Direct Chemical Assay with Isotopic Estimation)

\begin{tabular}{|c|c|c|c|c|c|c|}
\hline & \multicolumn{2}{|c|}{$\begin{array}{c}\text { Control } \\
\text { i.v. }\left[{ }^{14} \mathrm{C}\right] \text { Cholesterol }\end{array}$} & \multicolumn{2}{|c|}{$\begin{array}{l}\text { Cholesterol-fed } \\
\text { Oral }\left[{ }^{2} \mathrm{H}\right] \text { cholesterol }\end{array}$} & \multicolumn{2}{|c|}{$\begin{array}{c}\text { Bile-diverted } \\
\text { i.v. }\left[{ }^{14} \mathrm{C}\right] \text { Cholesterol }\end{array}$} \\
\hline & A & B & C & $\mathrm{D}$ & $E$ & F \\
\hline \multirow{3}{*}{$\begin{array}{l}\text { Total carcass cholesterol } \\
\quad \text { (eviscerated and skinless), }{ }^{*} g \\
\text { Total carcass cholesterol } \\
\quad \text { (above minus nervous tissue)* } g \\
\text { Total exchangeable carcass cholesterol, } g \\
\quad \text { (from isotopic data) }\end{array}$} & 22.7 & 19.2 & 20.1 & 14.4 & 20.7 & 14.7 \\
\hline & 22.7 & 19.2 & $18.8 \ddagger$ & $11.0 \S$ & $19.4 \ddagger$ & 14.7 \\
\hline & 23.6 & 19.5 & 19.6 & 11.6 & 25.3 & 20.3 \\
\hline \multicolumn{7}{|c|}{$\begin{array}{l}\text { * From Table I. } \\
\ddagger \text { Table I shows that "eviscerated carcass" included the spinal cord. Therefore, the mean spinal cord cholesterol } \\
\text { content of dogs A, B, and F (=1.3 g) was deducted to give the result shown above. } \\
\S \text { Table I shows that "eviscerated carcass" included spinal cord plus brain. The value shown for dog D above } \\
=\text { "eviscerated carcass" minus the mean content of cholesterol in spinal cord plus brain in dogs A, B, and F } \\
(=3.4 \mathrm{~g}) \text {. }\end{array}$} \\
\hline
\end{tabular}

the tissues. The arteries appeared unremarkable and free of arteriosclerotic changes in all dogs.

In the bile-shunted dogs there were certain gross abnormalities. In $\operatorname{dog} F$ the liver was green but not hard or nodular. In dogs $\mathrm{E}$ and $\mathrm{F}$ the cholecysto-renal anastomoses were patent even though numerous irregular dark brown gallstones $(1 \mathrm{~cm}$ in diameter, or less) filled the biliary system. The intrahepatic bile ducts also contained numerous stones and sludge, and a few small stone fragments were found in the right ureter, but no stones were present in the urinary bladder. The stones were composed mainly of calcium bilirubinate: the principal organic compound behaved spectrophotometrically like bilirubin and the main inorganic substance was calcium (based on neutron activation analysis). The remnant of the right kidney used to establish the bilio-renal shunt appeared shrunken. The right ureter appeared slightly thickened and dilated but was not obstructed.

Abnormal histologic findings were limited to the biliary tract and the right urinary collecting systems of the two bile-diverted dogs; however, the urinary bladder was normal in both animals. In $\operatorname{dog} E$ there was mild pyelitis and right ureteritis; the liver histology was normal even though there were numerous bile pigment stones in the gallbladder and the major bile ducts. In $\operatorname{dog} F$ there were similar changes in the renal pelvis and right ureter; furthermore, there was a moderate degree of cholestasis (persistent mild elevation of serum alkaline phosphatase during life, greenish liver at autopsy), and of cholangitis. The latter was evidenced by the presence of polymorphonuclear leukocytes in the lumen of the bile ducts with flattening of their epi- thelium, along with a moderate degree of periductal fibrosis and inflammation. No bacteria were seen on histological sections.

The findings of cholangitis and cholestasis in one of the two bile-shunted dogs raises the question whether the results obtained here were due in part to some disturbance in liver function. We consider this unlikely, since the results in the nonobstructed dog were similar; because both dogs appeared clinically healthy; and because the antemortem cholangiograms showed patency of the biliorenal anastomoses in bath dogs. However, the formation of multiple bilirubinate stones in the biliary tree of both dogs raises the question whether bacterial deconjugation of bilirubin glucuronide had occurred in the anastomotic areas, as previously described in animals and in man (7). We have wondered also whether taurine depletion may have had a role in stone formation: since these dogs excreted taurine-conjugated bile acids only, it is reasonable to propose that taurine stores could have been depleted secondary to enhancement of bile acid synthesis; and that limitation of bile acid conjugation in the liver may have led to some increase in free bile acid concentration in the liver and thus to increased hemolysis and bilirubin excretion. These ideas remain to be explored.

\section{DISCUSSION}

The chief objective of this study was to measure during life and then at sacrifice the changes in body cholesterol pools that might have resulted after many months of high-cholesterol diets or complete bile diversion. Using sterol balance and isotope kinetic data obtained during life, we predicted no net accumulation of cho- 
lesterol in the body with high-cholesterol feeding (2); nevertheless, the significant rise in plasma levels suggested that appreciable increments might be found in certain tissue pools of cholesterol. In contrast, we knew of no method by which to predict during life whether the bile-diverted dog could maintain its body stores of cholesterol in the face of complete interruption of the enterohepatic circulation of cholesterol: after nearly $2 \mathrm{yr}$ of bile shunting and a substantial fall in plasma cholesterol, a parallel decrease in exchangeable tissue pools might have been expected.

Responses to cholesterol loading. This study demonstrated that there was no accumulation of cholesterol in any organ or tissue after high-cholesterol diets had been fed for many months. Through complete feedback inhibition of synthesis and accelerated conversion of excess absorbed cholesterol to bile acids, significant expansion of tissue cholesterol pools was apparently prevented. The validity of the conclusions obtained during life by the sterol balance and kinetic analysis methods was confirmed post mortem by direct analysis of tissue cholesterol contents and specific activities.

In the rat (8) and in some patients studied by the sterol balance method (9) compensatory responses also can be complete. In man, excess dietary cholesterol is re-excreted exclusively as neutral sterol while in the rat and dog the excess absorbed cholesterol is apparently excreted in the form of bile acids; in all three species, feedback suppression of synthesis can be demonstrated.

In contrast, high-cholesterol diets in rabbits, the rhesus monkey, and the hypothyroid dog readily induce hypercholesterolemia, accumulation of cholesterol in body tissues, and arteriosclerosis (10-12). Under these conditions, compensation for excess dietary cholesterol is clearly inadequate in these species, as well as in some patients (9). It is relevant to note that in the hypothyroid dog the conversion of cholesterol to bile acids may be blocked (13); under such deranged conditions one of the dog's main means of compensating for excess cholesterol absorption may be lost.

Responses to bile diversion. In the bile-shunted dogs, total body content of cholesterol was not depleted even though each animal excreted over a 2 -yr period about $1 \mathrm{~kg}$ of cholesterol in excess of that expected in the intact dog. Except for the plasma and liver, none of the other organs or tissues was depleted of cholesterol during this long period of maximal cholesterol excretion. Thus, the critical data required at sacrifice of these dogs proved that the large amounts of sterols and bile acids excreted by these dogs were entirely due to increased synthesis secondary to release of feedback control mechanisms.
These findings in the bile-diverted dog, in which tissue pools of cholesterol essential for normal structure and function were not depleted, stand in striking contrast to the depletion of excess tissue stores of cholesterol shown to occur clinically in some hypercholesterolemic patients on being fed the bile acid sequestrant cholestyramine or by surgical exclusion of the terminal ileum, as judged by resolution of xanthomata (14). Analogously, the drug clofibrate causes a flux of cholesterol in man when tissue stores are swollen through years of hypercholesterolemia, but such fluxes are minimal or nonexistent in patients whose pools are not swollen (15).

Maintenance of the cholesterol stores required in tissues for essential structural purposes could not be assessed accurately during life in $\operatorname{dogs} E$ and $F$ : for this the measurements made at sacrifice were crucial. Moreover, the post-mortem data indicated that the cholesterol specific activities were very much higher in most tissues than in the plasma, except in liver and spleen. These findings are compatible with greatly increased cholesterol synthesis, consequent dilution of plasma cholesterol specific activity, and delayed equilibration between plasma and tissue cholesterol. Since tissue specific activities were measured only once, at sacrifice, it is impossible to draw the necessary tissue time-course curves; nor can we predict whether the decay curves in the tissues might have been falling in parallel to those in plasma, or at different rates, suggesting disequilibrium in the rate constants for these exchanges.

It is of considerable interest to us that our calculation of total exchangeable body cholesterol in $\operatorname{dog} \mathrm{F}$ by kinetic analysis of the decay curve of plasma cholesterol specific activity (Table $Y$ ) so closely matched the chemical measurement of total body cholesterol (exclusive of skin and CNS tissue): yet, the calculation of total exchangeable carcass cholesterol from tissue specific activity data in dogs $\mathrm{E}$ and $\mathrm{F}$ produced much larger pool size estimates than were obtained by chemical measurements made at time of sacrifice (Table VI). We conclude from the data in these two tables that $M$. $M_{A}$, and $M_{B}(\mathrm{~min})$ (by input-output analysis) (4) or pools A and B (min) (by compartmental analysis) (6) are valid measurements even in the face of greatly increased cholesterol synthesis rates (as in $\operatorname{dogs} E$ and F) ; but that the lack of equilibrium in specific activities between tissues and plasma under these circumstances renders invalid the calculation of pool sizes from tissue specific activity data.

Plasma cholesterol. From this and other studies it appears that plasma cholesterol concentration may be an imperfect indicator of tissue cholesterol content. 
Cholesterol balance data and isotopic studies in man suggest that large amounts of cholesterol can accumulate in body pools in the face of only a modest rise in plasma levels (9); in comparative studies of Japanese and Americans succumbing to sudden death, tissue cholesterol concentrations were remarkably similar despite sizable differences in plasma levels (16). Conversely, plasma cholesterol correlates well with tissue cholesterol content in the cholesterol-fed rhesus monkey (11).

Nonexchangeable pools of cholesterol. It is evident from Table VI that in the control and cholesterol-fed dogs (A-D), there was close correspondence between the measurements by chemical methods of the total carcass cholesterol (minus that in all viscera, skin, and nervous tissue) and the total exchangeable carcass cholesterol calculated from the isotopic data; these data are in complete concordance with the earlier results obtained in squirrel monkeys under similar conditions by Lofland et al. (5). Indeed, the approximation of these two estimates is so close that little or no "space" is left in these dogs for what Wilson (17) has called pool C (nonexchangeable or very slowly exchangeable cholesterol). He fed tritiated cholesterol orally for 120 days to five baboons, and also administered a single intravenous dose of $\left[4-^{14} \mathrm{C}\right]$ cholesterol before their sacrifice; as in the present experiment, he measured the cholesterol content and two sets of specific activities in many organs and tissues. From these data he calculated for each the amount of readily exchangeable cholesterol, and by difference from the total he estimated how much cholesterol in each specimen was very slowly exchangeable.

An important premise underlying his calculations was the assumption that the isotopic steady state had been attained, or at least closely approximated, in his baboons. His evidence that this steady state had been reached was based on inspection of the curve of plasma cholesterol specific activity, not (as in the present experiment) on demonstrating that the intake and output of radioactive materials had become equal. If, indeed, the isotopic steady state had not been reached in Wilson's animals due to the relatively short duration of his experiment, then the total exchangeable carcass cholesterol would have been underestimated, and consequently pool $\mathrm{C}$ would have been overestimated. In the 220-270-day studies of two cholesterol-fed dogs reported here, an isotopic steady state was proved to have been attained before sacrifice by demonstration that the daily excretion of labeled cholesterol equaled its intake. Furthermore, at sacrifice the ratio of tissue/ plasma specific activity (Table IV) was close to unity in all tissues, except brain, spinal cord, dura mater, and skin; these findings stand in contrast to those in
Table II of Wilson's report, which showed distinctly low ratios in adipose tissue, colon, stomach, muscle, bone, and aorta.

Wilson's conclusion that in these six tissues there were large amounts of nonexchangeable or very slowly exchangeable cholesterol was, in part, based on the data from which those low ratios were calculated. It is possible, however, that the ratios were low due to the short duration of his experiment and consequent failure to attain the isotopic steady state at the time of sacrifice. (As seen in Fig. 4 of the accompanying paper, the specific activity curves in the two dogs were far from the isotopic steady state at 120 days.) Wilson was reassured to find that his estimate of pools $\mathrm{A}+\mathrm{B}$ obtained by two-pool compartmental analysis (18) was very similar to his estimate of total exchangeable carcass cholesterol obtained during the "apparent isotopic steady state." But it is now known from studies in man $(4,19)$ that two-exponential analysis of decay curves determined for only about $12 \mathrm{wk}$ after administration of a single dose of radioactive cholesterol systematically underestimates the size of the exchangeable pools of cholesterol: if decay curves are carried out to $45 \mathrm{wk}$ or more, a third exponential can often be demonstrated, indicating the existence in man of a third pool that exchanges at a slower rate than pool $\mathrm{B}$. Thus, it seems possible to reconcile Wilson's experiment with our own by suggesting that he was measuring only the more rapidly exchanging pools of exchangeable cholesterol, whereas we have shown in a longer experiment that all the tissue stores (except those in nervous tissue and skin) eventually equilibrate with plasma cholesterol. However, if the isotopic steady state was not attained in his baboons, then his estimate of the sizes of pools $A+B$ would have been underestimates, and of pool $\mathrm{C}$ an overestimate, with the demarcation between $\mathrm{C}$ and the others an arbitrary one based purely on the duration of his experiment. It is possible, of course, that species differences may have contributed to the discordant results from our two laboratories, but it is of interest to note that Lofland et al. (5), in their careful long-term studies in squirrel monkeys, reached conclusions similar to ours.

\section{ACKNOWLEDGMENTS}

We are grateful to Drs. Paul Samuel and Sidney Lieberman for their computerized estimates of pool sizes and turnover rates, and to Mr. Albert Angevin, Mrs. Marilyn Aguirre, Miss Elsie Fonseca, and Mrs. Eleanor Mathusek for their excellent technical assistance. The use of the anesthetic and operating facilities of the Animal Medical Center of New York is gratefully acknowledged.

This work has been supported by U. S. Public Health Service grants GM 01706 and HL-06222 from the $\mathrm{Na}$ tional Heart and Lung Institute. 


\section{REFERENCES}

1. Grundy, S. M., and E. H. Ahrens, Jr. 1970. The effects of unsaturated dietary fats on absorption, excretion, synthesis and distribution of cholesterol in man. J. Clin. Invest. $49: 1135$.

2. Pertsemlidis, D., E. H. Kirchman, and E. H. Ahrens, Jr. 1973. Regulation of cholesterol metabolism in the dog. I. Effects of complete bile diversion and of cholesterol feeding on absorption, synthesis. accumulation, and excretion rates, measured during life. J. Clin. Invest. 52: 2353.

3. Miettinen, T. A., E. H. Ahrens, Jr., and S. M. Grundy. 1965. Quantitative isolation and gas-liquid chromatographic analysis of total dietary and fecal neutral steroids. J. Lipid Res. 6 : 411.

4. Samuel, P., and S. Lieberman. 1973. Improved estimation of body masses and turnover of cholesterol by computerized input-output analysis. J. Lipid Res. 14: 189.

5. Lofland, H. B., Jr., T. B. Clarkson, and B. C. Bullock. 1970. Whole body sterol metabolism in squirrel monkeys (Saimiri scicreus). Exp. Mol. Pathol. 13: 1.

6. Nestel, P. J., H. M. Whyte, and DeW. S. Goodman. 1969. Distribution and turnover of cholesterol in humans. J. Clin. Invest. 48: 982.

7. Maki, T. 1966. Pathogenesis of calcium bilirubinate gallstone. Role of $E$. coli, $\beta$-glucuronidase, and coagulation by inorganic ions, polyelectrolytes, and agitation. $A n n$. Surg. 164: 90.

8. Dietschy, J. M., and J. D. Wilson. 1970. Regulation of cholesterol metabolism. N. Engl. J. Med. 282: 1128, $1179,1241$.

9. Quintão, E., S. M. Grundy, and E. H. Ahrens, Jr.
1971. Effects of dietary cholesterol on the regulation of total body cholesterol in man. J. Lipid Res. 12: 233.

10. Ho, K. J., and C. B. Taylor. 1968. Comparative studies on tissue cholesterol. Arch. Pathol. 86: 585.

11. Armstrong, M. L., W. E. Connor, and E. D. Warner. 1969. Tissue cholesterol concentration in the hypercholesterolemic rhesus monkey. Arch. Pathol. 87: 87.

12. Steiner, A., and F. E. Kendall. 1946. Atherosclerosis and arteriosclerosis in dogs following ingestion of cholesterol and thiouracil. Arch. Pathol. 42: 433.

13. Abell, L. L., E. H. Mosbach, and F. E. Kendall. 1956. Cholesterol metabolism in the dog. J. Biol. Chem. 220: 527.

14. Grundy, S. M., E. H. Ahrens, Jr., and G. Salen. 1971. Interruption of the enterohepatic circulation of bile acids in man: comparative effects of cholestyramine and ileal exclusion on cholesterol metabolism. J. Lab. Clin. Med. 78: 94 .

15. Grundy, S. M., E. H. Ahrens, Jr., G. Salen, P. H. Schreibman, and P. J. Nestel. 1972. Mechanisms of action of clofibrate on cholesterol metabolism in patients with hyperlipidemia. J. Lipid Res. 13: 531.

16. Insull, W., Jr., S. Yoshimura, and T. Yamamoto. 1967. Comparison of cholesterol concentration in serum and liver of Japanese and American men. Circulation. 36 (Suppl. II) : 19

17. Wilson, J. D. 1970. The measurement of the exchangeable pools of cholesterol in the baboon. J. Clin. Invest. 49: 655 .

18. Goodman, DeW. S., and R. P. Noble. 1968. Turnover of plasma cholesterol in man. J. Clin. Invest. 47: 231.

19. Goodman, DeW. S., R. P. Noble, and R. B. Dell. 1973. Three-pool model of the long-term turnover of plasma cholesterol in man. J. Lipid Res. In press. 